7. Reprod. Fert. (1971) 26, 259-262

\title{
PLASMA PROGESTERONE CONCENTRATIONS DURING PREGNANCY AND PARTURITION OF EWES GRAZING YARLOOP CLOVER
}

\author{
J. M. OBST, R. F. SEAMARK AND C. J. McGOWAN \\ Department of Animal Physiology and Department of Obstetrics and Gynaecology, \\ University of Adelaide, and Department of Agriculture, Parndana, \\ Kangaroo Island, South Australia
}

(Received 22nd December 1970)

\begin{abstract}
Summary. Progesterone concentrations in the peripheral plasma of pregnant ewes grazing oestrogenic (yarloop clover) and non-oestrogenic (rye grass) pastures were compared. Whilst the overall pattern of plasma progesterone throughout pregnancy in the two groups was similar, the mean of values determined from the 90th day of gestation in ewes on yarloop was significantly lower than those on grass.

No significant differences were recorded in the length of pregnancy or birth weight of lambs $(P>0.05)$ although some evidence of maternal dystocia was obtained for the ewes on yarloop.

In relation to parturition, mean plasma progesterone values in both groups began to fall $96 \mathrm{hr}$ before birth, at first gradually then rapidly in the $16 \mathrm{hr}$ preceding birth. Ewes on grass had a higher $(P<0.01)$ plasma progesterone concentration 0 to $8 \mathrm{hr}$ before birth but neither the level nor the pattern of progesterone disappearance appeared to be related to the lambing difficulties observed.
\end{abstract}

Two classical symptoms of clover disease in ewes, infertility and dystocia were described by Bennetts, Underwood \& Shier (1946). Determination of plasma progesterone concentrations throughout the oestrous cycle of young ewes grazing oestrogenic (yarloop clover) pastures indicated that corpus luteum function in the infertile animals was reduced (Obst \& Seamark, 1970). To investigate the possibility of there being similar endocrinological disturbance underlying dystocia, the concentrations of plasma progesterone of pregnant ewes exposed to oestrogenic pastures have been determined throughout pregnancy and parturition. The observations made reveal that plasma progesterone levels in ewes grazing yarloop pastures are significantly lower in late pregnancy than those found in ewes grazing non-oestrogenic pastures.

The experimental animals were from a mixed flock of $3 \frac{1}{2}$-year-old ewes of the Merino and Corriedale breed held on the Department of Agriculture Research Station at Parndana on Kangaroo Island. Eighty-six of the ewes were mated in February 1970 on dry yarloop pasture and eighty-four on rye-grass pasture, to rams fitted with sire-sine harnesses and crayons. Matings were recorded every 
day. Ten ewes holding to first service were selected from each group and bled by venipuncture once weekly throughout pregnancy and parturition. Ten days before the expected date of parturition, bleeding frequency was increased to once every $8 \mathrm{hr}$ and this continued until $24 \mathrm{hr}$ post partum. The blood samples were centrifuged and the plasma frozen immediately after collection and stored at $-14^{\circ} \mathrm{C}$ until assay.

Plasma progesterone determinations were made using the competitive protein binding assay outlined previously (Obst \& Seamark, 1970). To minimize possible errors due to between-assay variability, samples from ewes grazing grass and yarloop pastures were analysed in the same assay.

The fertility of ewes grazing yarloop clover was clearly affected, only fiftyeight $(67 \%)$ lambs being born to ewes on the yarloop compared with eightyfour $(100 \%)$ on grass. Higher lamb mortality (45\% compared with $26 \%)$ and ewe mortality ( $12 \%$ compared with $2 \%$ ) was also recorded, the higher incidence of lamb and ewe deaths on yarloop being associated with foetal retention and dystocia. Mean gestation lengths for the two groups were, however, similar, $150.5 \pm 1.06$ (S.E.M.) and $151.4 \pm 1.70$ days for grass and clover groups, respectively.

Of the ewes selected for bleeding, nine of the ten grazing grass produced normal healthy lambs (mean birth weight $4.05 \pm 0.47 \mathrm{~kg}$ ), including one set of twins. Lambing difficulties were recorded in one ewe taking $120 \mathrm{~min}$ to complete parturition and delivery of a single large $6.7-\mathrm{kg}$ lamb, parturition in this study being defined as the time from first appearance of the front feet to complete delivery, normally less than $30 \mathrm{~min}$.

Only six of the ewes grazing yarloop had normal deliveries. Seven lambs were produced (mean birth weight $4 \cdot 15 \pm 0.25 \mathrm{~kg}$ ), including one set of twins. Three ewes experienced prolonged parturition. Of these, two delivered viable single lambs weighing $4.4 \mathrm{~kg}$ and $4.3 \mathrm{~kg}$ after 61 and 117 min respectively and one required assistance to deliver dead twin foetuses. The remaining ewe died on the 164th day of gestation without showing signs of lambing and was found at post mortem to contain a mature but partially mummified foetus.

Mean plasma progesterone values for the surviving ewes are shown in Textfigs. 1 and 2.

Progesterone levels during pregnancy in the grass group were similar to those reported by Bassett, Oxborrow, Smith \& Thorburn (1969) and Fylling (1970). The levels in ewes grazing yarloop, whilst showing a similar overall pattern to ewes on grass, were significantly lower from 90 th day of pregnancy (Text-fig. 1). Data obtained from more frequent bleedings during the last 9 days of pregnancy (Text-fig. 2) indicated that these differences tend to be maintained during the period of declining plasma progesterone levels which precedes parturition.

The finding that progesterone levels in early pregnancy are similar in the grass and yarloop groups is in agreement with our previous studies (Obst \& Seamark, 1970) and suggests that once pregnancy is established, luteal function is not affected by ingestion of yarloop. In late pregnancy, however, when gestagenic hormones mainly stem from an extraovarian source (Mattner \& Thorburn, 1971), yarloop ingestion appears to reduce plasma progesterone 


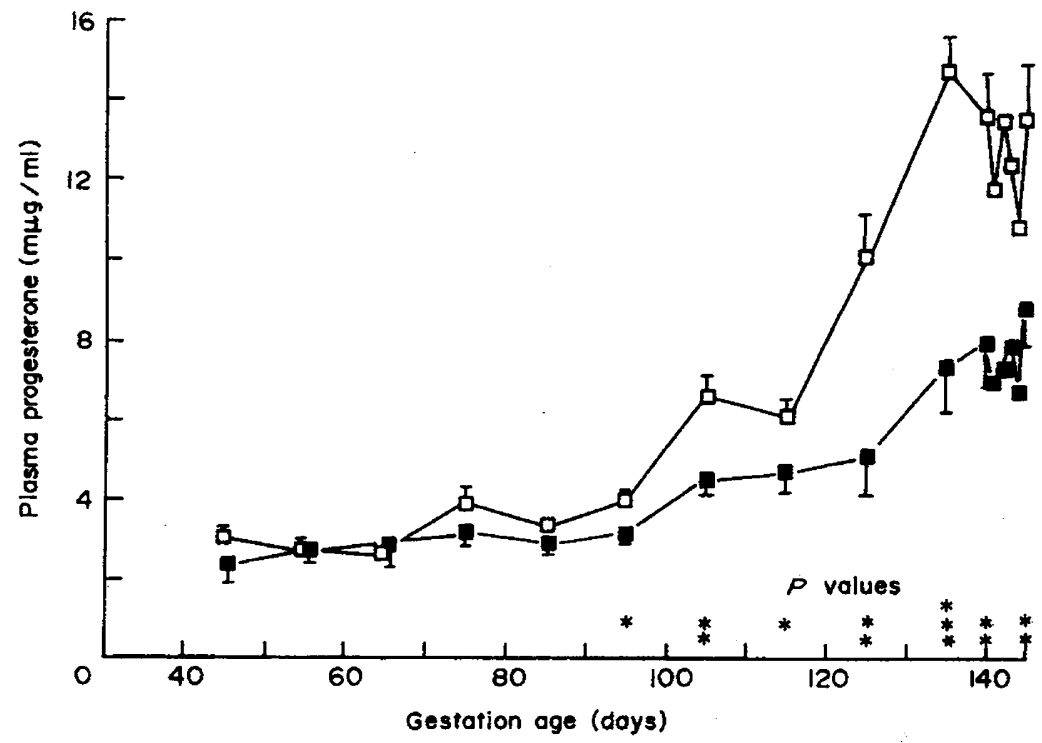

Texr-pIG. 1. Plasma progesterone concentrations of pregnant ewes grazing oestrogenic $(\square)$ and non-oestrogenic $(\square)$ pasture. Determinations were made at weekly intervals. Each point represents the mean value $( \pm$ S.E.M.) for nine ewes.

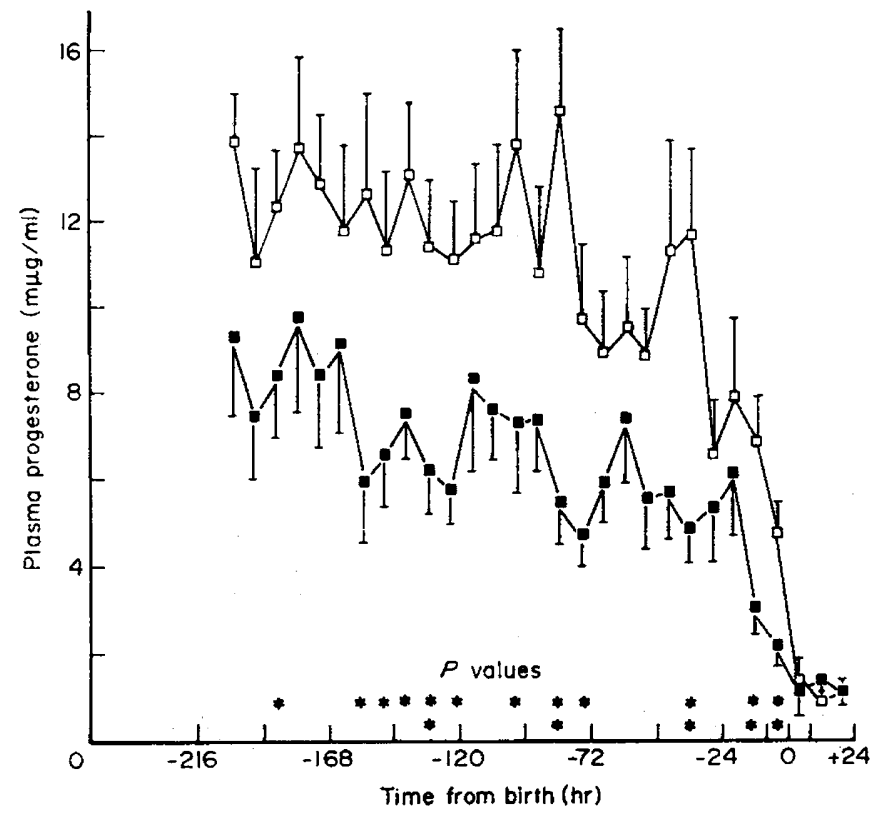

TEXT-FIG. 2. Plasma progesterone concentrations of pregnant ewes grazing oestrogenic (D) and non-oestrogenic (ㅁ) pasture. Determinations were made at 8-hr intervals. Each point represents the mean value $( \pm$ S.E.M.) for nine ewes. 
levels. Whether yarloop exerts these effects by acting directly on the endocrine glands or indirectly through altering the metabolic clearance rate of progesterone remains to be determined.

The similar birth weight of lambs in both groups indicates that the lower progesterone values had not affected intrauterine growth. The possibility of decreased placental function is not excluded by these observations as quite marked reductions in placental mass can be tolerated in sheep without a significant effect on foetal growth rate (Alexander, 1964).

The lowered progesterone values in ewes grazing yarloop might be expected to cause difficulties in pregnancy maintenance and parturition. Progesterone is known to act during pregnancy by blocking myometrial activity which would lead to expulsion of the foetus. Removal of this block is associated with parturition (Hindson, Schofield \& Ward, 1969). However, delayed rather than premature parturition is observed with clover disease and maternal dystocia is common (Bennetts et al., 1946; Maxwell, 1970).

The changes in the pattern of plasma progesterone concentration in relation to parturition were remarkably similar in the two groups. In both, the fall in plasma progesterone began about $96 \mathrm{hr}$ before birth, being at first gradual then falling rapidly in the 16 to $24 \mathrm{hr}$ before birth. The rate of disappearance of progesterone in the two groups was similar but, owing to the higher initial concentration in ewes on grass, significantly more $(P<0.01)$ progesterone remained in their plasma 0 to $8 \mathrm{hr}$ before parturition than in ewes on yarloop. No relationship, however, could be established between the individual patterns and observed lambing difficulties. Most probably, the low level of progesterone reflects more general metabolic and endocrine disturbances and these underly the recorded dystocia.

Financial assistance from the Australian Wool Board is gratefully acknowledged.

\section{REFERENGES}

AlEXANDER, G. (1964) Studies on the placenta of the sheep (Ovis aries $L$ ). Effect of surgical reduction in the number of caruncles. F. Reprod. Fert. 7, 307.

Bassetr, J. M., Oxborrow, T. J., Smith, I. D. \& Thorburn, G. D. (1969) The concentration of progesterone in the peripheral plasma of the pregnant ewe. F. Endocr. 45, 449.

Bennetts, H. W., Underwood, E. J. \& ShIER, F. L. (1946) A specific breeding problem of sheep on subterranean-clover pastures in Western Australia. Aust. vet. 7. $22,2$.

Fyluing, P. (1970) The effect of pregnancy, ovariectomy and parturition on plasma progesterone level in sheep. Acta endocr., Copenh. 65, 284.

Hindson, J. G., Schopield, B. M. \& Ward, W. R. (1969) The effect of progesterone on recorded parturition and on oxytocin sensitivity in the sheep. $\mathcal{F}$. Endocr. 43, 207.

Matrner, P. E. \& Thorburn, G. D. (1971) Progesterone in utero-ovarian venous plasma during pregnancy in ewes. F. Reprod. Fert. 24, 140.

MAXWELL, J. A. L. (1970) Field observations on four outbreaks of maternal dystocia in the Merino ewe. Aust. vet. F. 46, 533 .

Obst, J. M. \& Seamark, R. F. (1970) Plasma progesterone concentrations during the reproductive cycle of ewes grazing yarloop clover. 7. Reprod. Fert. 21, 545. 